\title{
Research on the Metaphor Discourse Construction and Translation Strategies from the Perspective of the Framework
}

\author{
ZhangDonghua \\ Nanchang Institute of Science \&Technology,Nanchang 330108,China
}

Keywords: Framework, Discourse function, Translation strategies, Reading ability, Metaphor.

\begin{abstract}
The human brain can relate to the existing knowledge experience in a specific situation with the help of the framework, people can construct a new cognition, so a concept framework builds gradually with the gradually familiar. In order to improve the translation ability of metaphor literature, this paper proposes a translation strategy based on framework, and the mutual relationship based on one or multiple frames, and then this paper uses the known knowledge experience to infer the understanding discourse meaning and the speaker's intention. Finally, through the method of teaching experiment, we can be statistically the use frequency of metaphor discourse function, and we analyze the influence on the reading ability after using the translation strategies of metaphor discourse function. The test results show that the use of metaphor framework can significantly improve students' reading ability, thus improving the translation ability.
\end{abstract}

\section{Introduction}

Lakoff has carried out the systematic study on the metaphor function in political discourse, trying to explain the different political standpoints and ideas of the Republican Party and democrats by means of metaphor [1-3]. Many western scholars have studied the metaphors in the news and political discourse, and discussed the social problems reflected in metaphor. Charteris-Blacks first proposed a critical discourse analysis of metaphor, and launched a systematic study combined with the critical discourse function and metaphor. People concerned about the social relations and the ideological problems reflected in the discourse, which aims to identify the metaphor method of the intent and ideology in the discourse [4-6]. Only by grasping the frame structure of metaphor, we can construct the functional framework of metaphor better, so that we can better identify the metaphor method, which has important significance on the study of translation strategies.

\section{The Critical Analysis of Conceptual Metaphor under Theoretical Framework}

Through the frame function, the discourse function of metaphor can be realized. While reading, the reader's understanding of the discourse is placed in one or more frames, and then the use of their own experience and knowledge background as well as concept structure infers the intent of the speaker, and the process is as follows [7]:

Figure 1 shows the flow chart of the metaphor framework, and then judge whether it is able to realize the function of discourse. If it cannot be realized, then reconstruct carries out the framework; if it is not needed, then judge whether the framework is able to realize the information; if the connection of information is realized, it can produce a new translation cognition; if the connection of information is not realized, it can start building a metaphor framework. The construction of the framework provides the context of things, so that it provides a new perspective for the interpretation and perception of things. Through the framework, the human brain can combine the background knowledge in a specific situation, forming a new cognitive structure. The conceptual framework is mainly people gradually familiar with the process of establishment, a part of the framework is inherent, and other framework is built up and applied to the translation practice. 


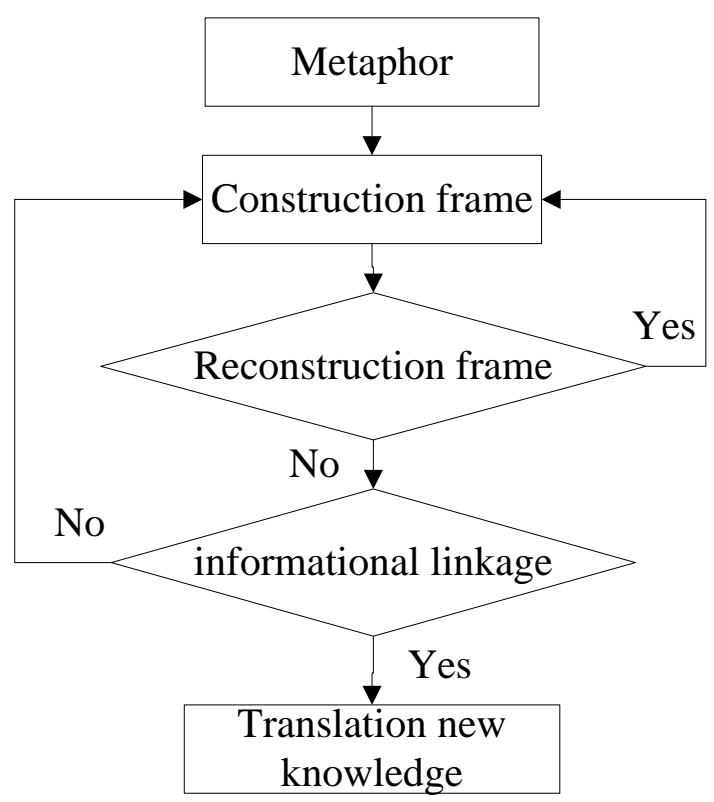

Fig.1 The metaphor framework construction process

\section{The Metaphor Translation Strategies from the Perspective of the Framework Theory}

In 1988, Snell-Hornby proposed frame semantics for the significance of translation studies. However, after the proposed 20 years, the perspective of the framework was still at the edge of the position, and the use of frame theory was not much research on translation [8-10]. Western scholars mainly caught out translation studies from the four aspects of the framework, the first level of research was theoretical discussion, the second level was the combination of other theories and frameworks, the third levels was the main research on cross disciplines to carry on classification study involved in the translation framework of cultural factors, and the fourth level was the use of framework theory to explore the specific translation [11-13]. Compared with the previous three aspects, the translation problems pays more attention to the practice, and the use of translation strategies is more able to highlight the framework linguistic theory, which embodies the dynamic construction process of the framework; when considering cultural factors, the translator determines the semantic choice based on the cultural context, and is embodied in the process of translation.

The Frame Transplantation of Metaphor Image. According to the theoretical perspective of the framework, the understanding of language is stimulate the memory of the brain storage generally based on the specific context, and then to choose the appropriate framework for the knowledge system. This frame is a kind of mental picture, understooding a word can be full of mental picture, and then focusing on the meaning of words [14]. Because different cultures have the same or different nature, metaphor is divided into general metaphor, cultural overlap metaphor and cultural Limited metaphor. For example, the famoous “do-nothing congress”of 1947-1948? It passed 906 Laws-710 more than the current grouphad passed entering its lame-duck session.

The frame conversion of metaphor image. Different frames are activated by different scenarios, if the source language readers and the target language readers experience are not the same, the two will be in a different framework, so the activation of the situation will be different. The construction of meaning is the dynamic linking process of the actual spatial components. Meaning is generated in a specific context, no specific context is not formed, and the conversion of transplantation is an ideal translation strategy, but the metaphor image framework can be converted to the target language, it will be restricted by the cultural framework [15]. Because the target language can not find the same metaphor, it will lead to cultural default; if the cultural default causes the reader to not find the answer in the text, so it will be the vacuum of the significance because of the cultural default.

Metaphor framework conversion as a moral. Another major cultural default of metaphor is for the non target language readers, the textual information is not related to the experience outside the text, so that we need to reconstruct the understanding of semantic coherence and situational 
coherence. Since the author uses an innovative metaphor image, we must abandon the original metaphor image frame in order to solve this problem, so that we will embody the moral.

\section{Metaphorical Discourse Function English Teaching Translation Strategies}

In order to study the construction of discourse function on the influence of the translation strategies in the framework, we use the experimental teaching method carry out statistical analysis of the translation strategies. This experiment selects a group of metaphor frames sample sequences and statistics the emergence frequency of the metaphor translation strategies. The statistical results are obtained as shown in Figure 2.

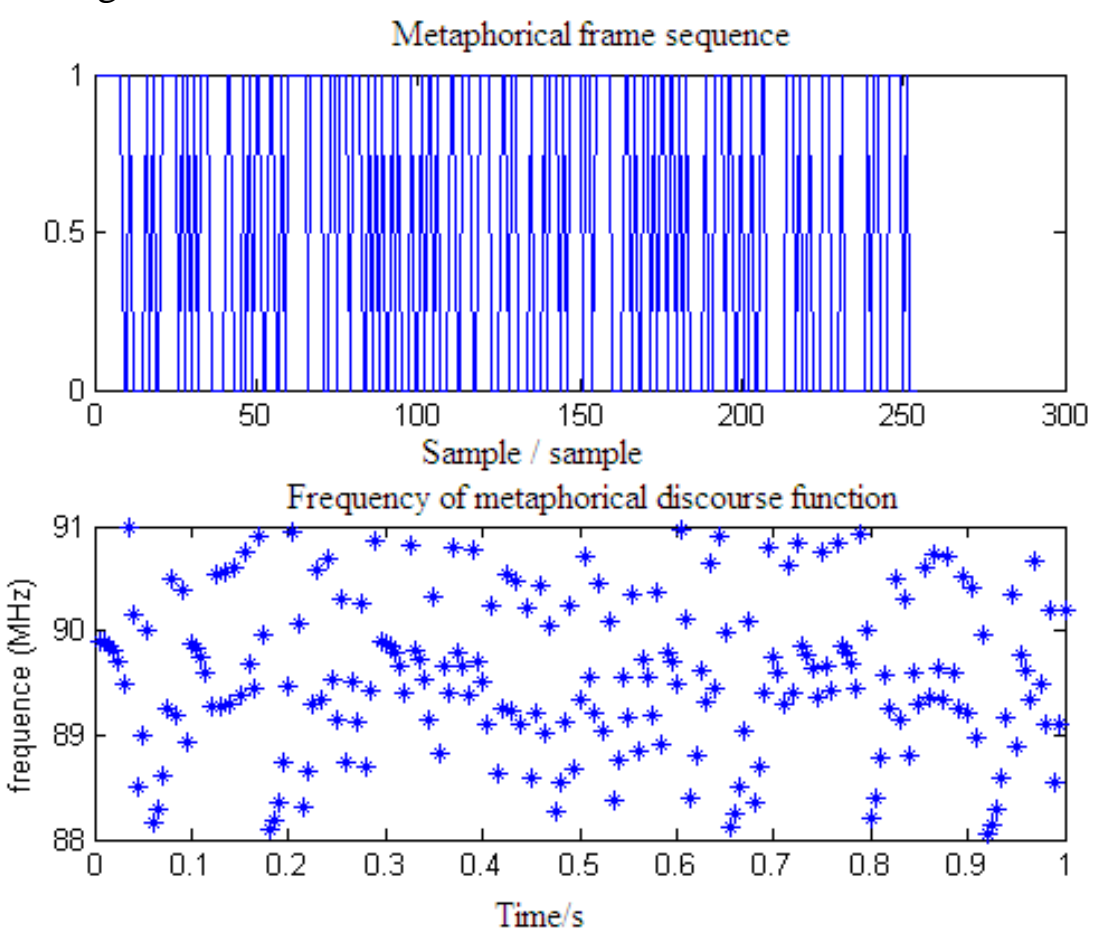

Fig.2 The realization of the frequency diagram of metaphor frame discourse function

Figure 2 shows the realization of the frequency diagram of metaphor frame discourse function. From the Figure 2, it can be seen that with the increase of time, the frequency distribution of the discourse framework is diversified, and it runs through every time. This shows that the framework of metaphor has a great influence on the function of discourse. In order to further study the effect of this kind of influence, the results of the teaching experiment are analyzed, and the results are shown in Table 1.

Table 1. Teaching effect statistics

\begin{tabular}{|c|c|c|}
\hline Experiment times & $\begin{array}{c}\text { The average score of the experimental } \\
\text { group (points) }\end{array}$ & $\begin{array}{c}\text { The average score of the } \\
\text { control group (points) }\end{array}$ \\
\hline 1 & 22.5 & 18.5 \\
\hline 2 & 21.2 & 17.2 \\
\hline 3 & 23.6 & 19.3 \\
\hline 4 & 22.1 & 19.6 \\
\hline 5 & 21.6 & 18.6 \\
\hline 6 & 23.8 & 17.8 \\
\hline
\end{tabular}

Table 1 shows the statistical analysis of the teaching experimental results, and the test project is main reading comprehension test. From the test result analysis, we can see that the performance of the experimental group is significantly higher than the control group, which is due to the framework of discourse function adopted by the experimental group to construct a translation strategy, and the subject of this test is focused on the problem of metaphor. Therefore, the experimental group is better on the content of the article, and can obtain higher score. 


\section{Summary}

This study makes the thorough study of the discourse function framework, and it is applied by the translation strategy. Through the study, we find that in the process of reading. The reader's understanding discourse is placed in one or more frames, and will be able to use the known knowledge experience inference and understanding discourse speaker's intention. The framework provides a specific context for people to understand things, and the reconstruction framework provides a new perspective for people to perception, interpretation and response of things, which can effectively improve the translation level of metaphor literature.

\section{References}

[1] X.L. Quan. The reconstruction translation framework as the translation purpose - Lin Shu's novel translation from the perspective of Mona Baker's narrative theory, Journal Huaibei normal university, 2012 (2): 117-121.

[2] L. Shao. the narrative interpretation of Translation and Syria in life and death. Shandong foreign language teaching, 2014(6): 96-101.

[3] L. Shao. The analysis of Mo Yan's life and death in the translation narrative world. Foreign language teaching and research, 2013(2): 68-71.

[4] L. Shao. The narrative stylistic trend in western translation theory. Foreign language studies, 2015(4): 86-92.

[5] B.W. Shang, Q.S. Hu. The study of the category and trend on the narrative after classic and post classic. Contemporary foreign literature, 2007 (3): 120-128.

[6] B.W. Shang. Beyond and trend: the postclassical narratology existence dimension omitted. Academic forum, 2014(3):167-173.

[7] J. Deng. Analysis on the frame semantics of translation studies. Foreign language teaching and research, 2014(1): 66-71.

[8] M.Y. He. The relationship identification between conceptual metaphor and politics. Foreign language, 2013(3): 48-52.

[9] S. Li. The construction and reconstruction of the framework in political speech as the case study of the cultural signs, metaphor and negation. Journal of Hainan University, 2013(5): 112-115.

[10] L.N. Wang. Review on the current situation of domestic news frame. Journal of Zhongzhou, 2013(6): 253-255.

[11] J.X. Xiao, H.W. Li. Study on the metaphor translation in the perspective of conceptual metaphor. Chinese foreign language, 2013(5): 106-111.

[12] W.Z. Xu, B.H. Xu. The implications of the framework sources and its application in translation studies. Journal of China University of Petroleum, 2013(5): 94-96.

[13] Q. Yao. The framework theory and the equivalent translation under the perspective of cognitive linguistic translation, 2014(5): 127-131.

[14] Y. Zhou. The metaphor translation under the framework theory. Foreign language literature, 2014(2): 117-120.

[15] Y.S. Zhu. The implications of the framework theory for the dynamic study of context. Foreign language and foreign language teaching, 2015 (2): 1-4. 